\title{
Functional features of the automated accounting and control system of signalling, centralization and blocking devices
}

\author{
Dilshod Baratov ${ }^{*}$ \\ Tashkent State Transport University, Tashkent, Uzbekistan
}

\begin{abstract}
The article illustrates the functional features of the automated system of operation of signalling, centralization and blocking devices, shows the interface of the automated system of accounting and control of railway automation and telemechanics devices, presents the system requirements and testing of the automated method. The process manages, and metering devices of automatics and telemechanics in the use of QRcoding method should be used for automated identification of devices of signalling, centralization and blocking with the aim of collecting data about installed devices, checking the correct replacement devices, data input on the implementation of the repair and acceptance, automated input of data on new devices submitted for repair and process areas.
\end{abstract}

\section{Introduction}

Currently, in connection with a significant increase in the volume of the building and technical renovation, the organization of velocities traffic, "Uzbekistan Railways", faces the task of significantly reducing the time and value of building of signalling, centralization and blocking (SCB) systems. And for this, it is necessary to develop methods that ensure control of the full life cycle of railway automation and telemechanics systems during the development, projects, construction, commissioning, operation, improvement and disposal of the process utilizing the automatic technology process and the use of electronic document management $[1,2]$.

Considering the above, in modern conditions, there is a significant increase in the level of functionality of the latest automation and telemechanics systems, an increase in their ability to receive and provide information for all services related to the organization of train traffic, the operation of signalling systems, monitoring the train position and the state of systems and devices, providing movement [3]. The further development of railway transport systems, naturally, leads to an increase in their complexity and, as a consequence, to the complication of their design, an increase in the number of subcontractors involved in the design, construction and supply of devices, structures and components, a complication of the processes of finding and eliminating failures in systems, increasing the time for checking systems during their commissioning $[4,5]$.

"Corresponding author: baratovdx@yandex.ru 
Thus, at the present stage of development of information systems of "Uzbekistan Railways", the creation of signalling systems must be introduced using the latest design methods, an automated system for organizing interaction, quality control of work on entering and receiving information [6,7]. Therefore, the only way out at the present level of improvement of railway automation and telemechanics is the creation of an integrated monitoring and management system for design, construction, commissioning, supplies of devices, materials, tools and analysis of the quality of service performed on the basis of automated methods.

Signalling and communication specialists have a special role in improving the efficiency of the industry and ensuring train traffic safety. The successful solution of problems will be facilitated by the creative interaction of the workers of this most complex production and technological complex.

\section{Methods}

This paper considers an automated control and accounting system for railway automation and telemechanics devices (ACA-SRAT).

Window interface of the automated system. The organization of the collection and transmission of information within the framework of the task "Initial data entry on devices" is carried out by the senior electromechanics of the station. The senior electromechanics of the repair and technological section (RTS) performs the initial filling of the database (DB) with information about the distance devices. In case of loss of data on devices or their incompleteness, the senior electromechanical prepares form templates for the inventory of devices and their location at a distance, the senior electromechanics or the complex replacement team fills out these forms. It sends them to the RTS, after which this information is entered into the ACA-SRAT.

The order and means of filling the database. The input data is entered manually from the computer keyboard in an interactive mode supported by the software according to the input layouts. When entering information, formal and logical control methods are used to prevent the entry of erroneous parameters (checking data for presence in directories, checking the uniqueness of a record, etc.). Maintaining the integrity of the database, copying and restoring is carried out by the database administrator by means of the SQL server.

Database modification and control procedures. Correction of errors made when entering information at a distance and entering additional data at a distance in the same mode as during the initial input.

Setting up an automated system. Access is configured by the administrator before installing ACA-SRAT. In the future, this mode is available only to the administrator to check and correct access to data (for example, when changing the server address). To configure access to data, you must specify:

- server name;

- database name.

When starting an automated system, it is necessary to identify it, if it has not been done before, when starting the Common taskbar.

The architecture of the windows of an automated system consists of three levels: the program window, the login and the window views (Fig. 1).

It is displayed as the main form in the program window. The system is logged in through the login form. The work in the automated system is carried out through the windows "New data", "View data", and "QR-code", which, in turn, are divided into subwindows. 
In the "Identification" window that appears (fig. 2), it is necessary to authorize the user. Find the user in the drop-down list of the "User" field. The brigade's name (or the surname of the chief) in which this user is located is indicated in brackets.

ACA-SRAT is installed on a computer in the RTS, and is a task for controlling the operation of the RTS. It is used to maintain a database on the movements of numbered and non-numbered devices and generate the documentation necessary for drawing up work plans for the RTS distance, RTS branch, as well as individual plans for RTS employees.

Appearance of the automated system. The ACA-SRAT user interface is shown in Fig. 3. The automated system is focused on using a multi-window environment with a standard interface - a set of data entry and information display tools:

MENU — a means of selecting a mode and entering basic commands;

WINDOW - means for displaying information;

DIALOG — data input tool;

STATUS BAR - displays the state of the program and the main commands of the program.

At the start of ACA-SRAT, by default, a window of the distance objects tree opens. This tree changes dynamically, and the time to open some branches may change.

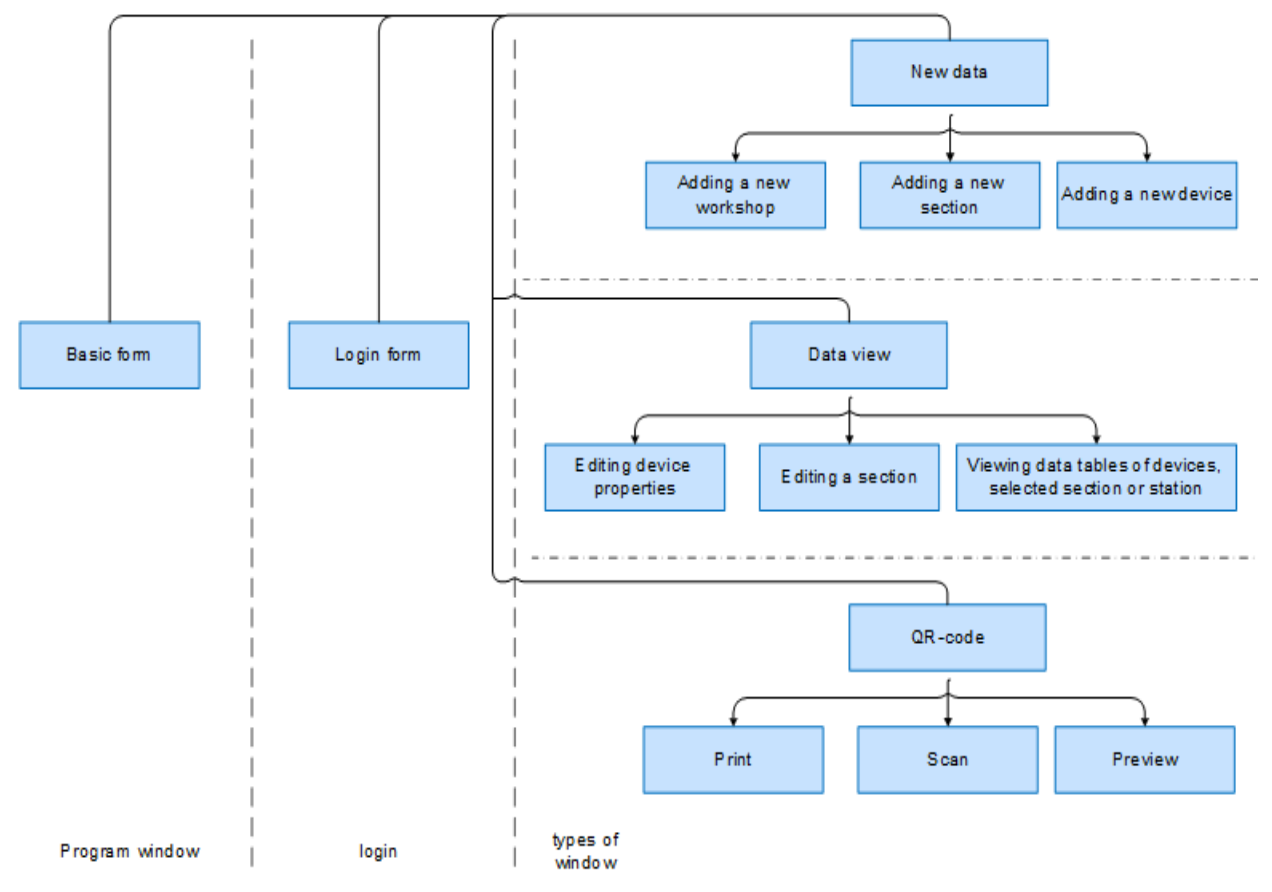

Fig.1. System windows architecture 


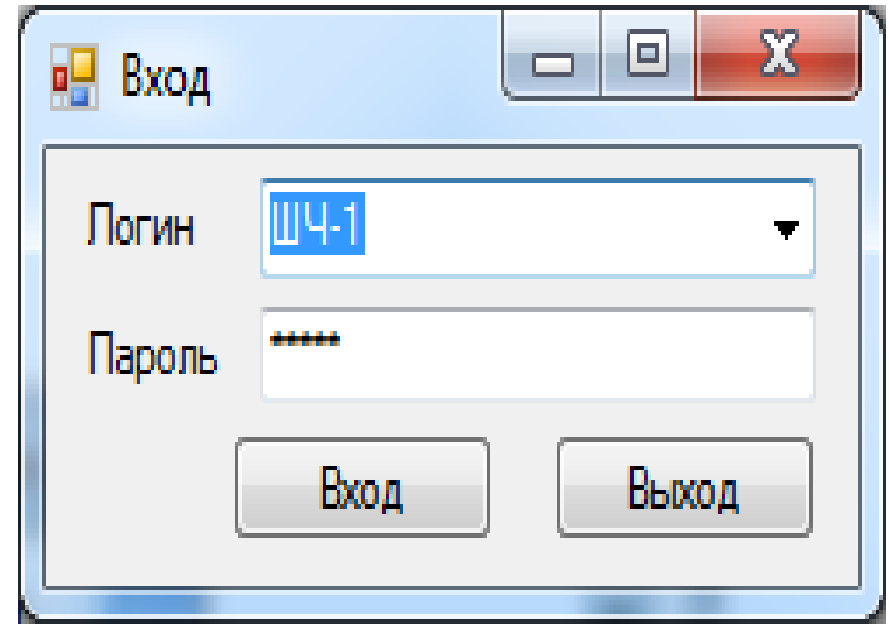

Fig. 2. Registration window

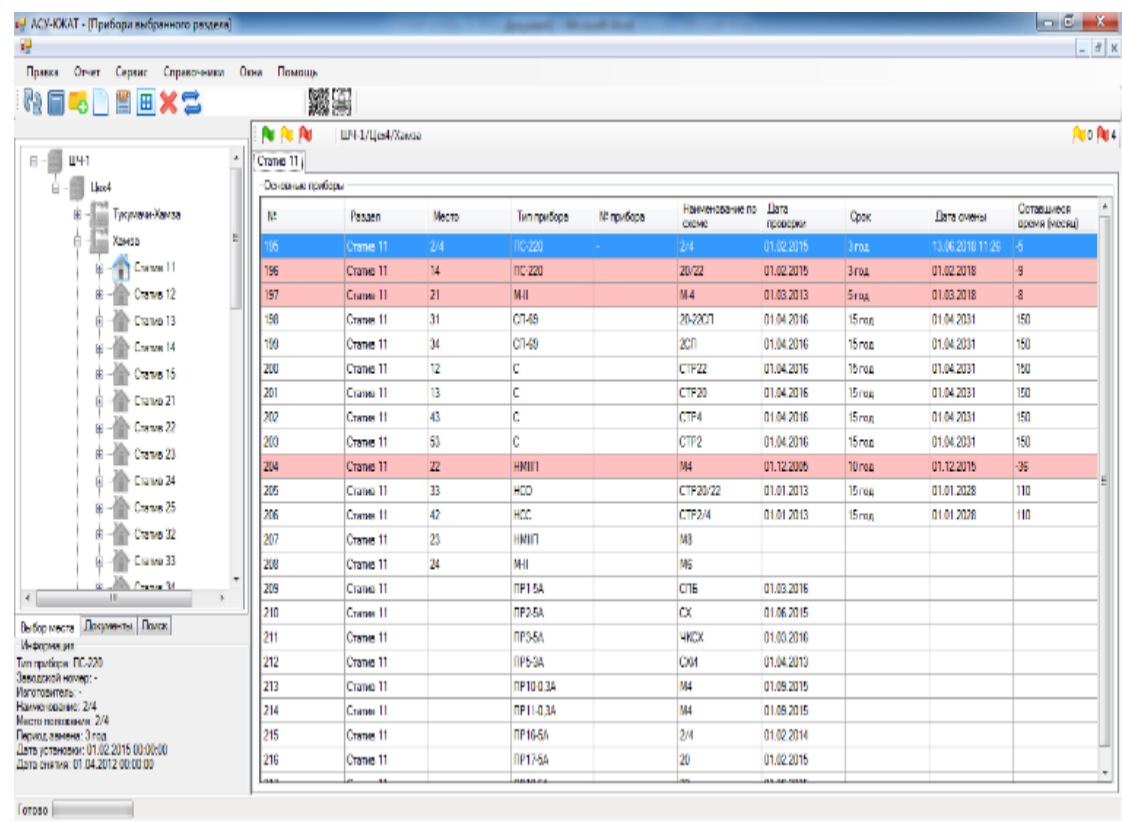

Fig. 3. System interface

The main objects of the program are lists of devices and places of installation of devices, documents (forms). When carrying out a planned replacement, the lists are displayed in pairs: one (lower) list of field devices and empty places-where the device can be installed or an existing one can be replaced, and the second (upper) list is a list of devices that can be replaced.

The name of the list is created based on the parameters for opening the list ([Station / Ferry] / Facility / Equipment) or taken from the database, if the list is obtained by queries stored in the database or when loading a replacement card.

Description of working toolbars. The program uses several toolbars to simplify work with forms, a list of fixtures, replacement plans, etc. Panels of the list of devices and installation locations are shown in Figure 4. 


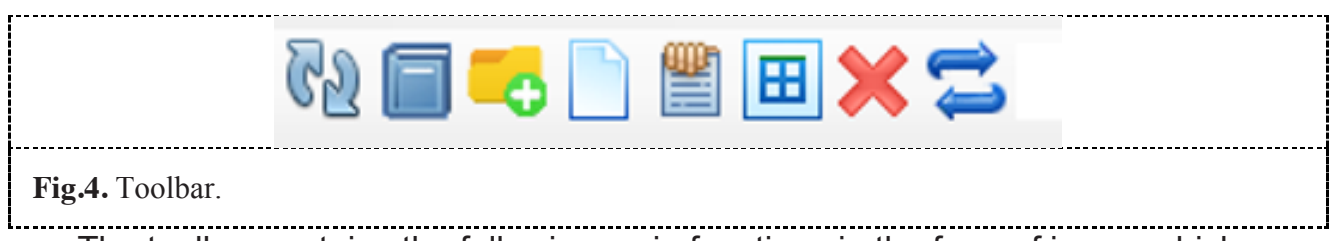

The toolbar contains the following main functions in the form of icons, which

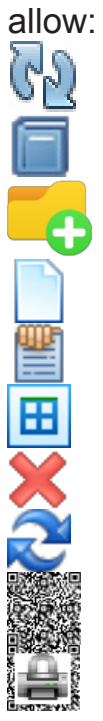

update information;

add a workshop for signaling and communication distance

add a separate item;

add a device;

edit information about the device;

viewing information about the devices;

remove the device;

replace the device;

read the QR-code of the device;

print the QR-code of the device.

Functional features of the system. The automated accounting and control system of SRAT devices is designed to automate the accounting and control of railway automation and telemechanics devices and plan the work of a repair and technological section (RTS) or a control and measuring point. The conceptual model and structure of data processing of the automated system for accounting and control of signalling systems are presented in Figure 5.

The automated system is used in railway automation and telemechanics distances. The main functions of the automated system:

- creation and maintenance of a database, including passports of specific devices and information about the place of their installation;

- tracking the movement of devices in connection with periodic replacements, writeoffs, receipts, etc.;

- planning the replacement of devices with the issuance of technologically necessary information;

- monitoring the implementation of plans for the replacement of devices;

- analysis of failures of devices of alarm devices, centralization and blocking;

- planning the work of repair and technological areas;

- issuance of output documents, the ability to search for devices in the database for arbitrary requests.

The functioning of ACA-SRAT is based on the use of a special program - a document management server. The server carries out the main functions that ensure users' work: search for equipment from the database, report on the number of devices, and read a $\mathrm{QR}$ code. Until the main program is launched, user interaction with the document management system and work with documents is impossible. 
The ACA-SRAT server program is executed on a computer connected to the signalling and communication distance network, which is also called a server. It is possible to select a separate computer for the server or use one of the network workstations. However, it should be noted that registering new instruments and generating instrument-related jobs and reports will increase the size of the database and the disk space it occupies, so you should ensure that you have sufficient hard disk capacity to take into account the growth prospects of information flow.

The administrative part of the program. A system with which many users work should have centralized management [8-14]. This function is performed by a specially designated employee or employees who implement a single consistent policy for setting up and managing the system called system administrators.

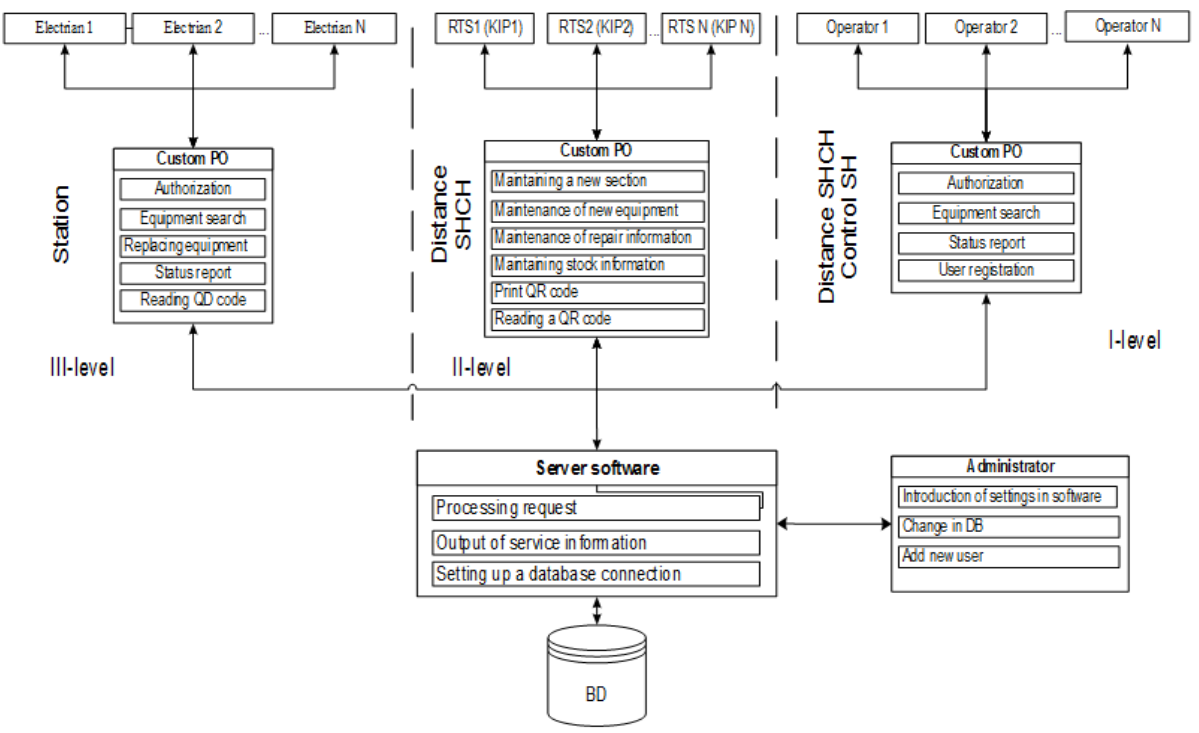

Fig.5. Conceptual model of the automated system for accounting and control of signalling systems

The responsibilities of the system administrator include, in particular, the following:

- reflection in the system of the current structure of the organization;

- registration of users;

- viewing system messages and error messages;

- updating database tables.

In addition to these functions, the system administrator also provides starting and stopping the ACA-SRAT server, configuring and maintaining the system, creating backup copies of the system databases and restoring the system in case of failures.

\section{Results and Discussion}

Using part. Signalling and communication distance employees registered in the system determined by their job duties are called system users. Depending on the type of activity, the system user is assigned by the administrator the rights to perform certain actions and access certain functions.

Functional features of the system. After connecting to the user's server, the main window is presented for working with the program. In essence, it is an SDI (single document) window with a main menu and toolbar. In this dialog box, all the basic 
functionality of the automated system is presented to the user in an ergonomic manner, namely:

- input of data about devices;

- device receipts;

- write-off of devices;

- devices exit from repair;

- planned replacement of devices;

- stock of devices;

- dismantling of devices.

The scheme of functioning of the user part of the automated system of accounting and control of signalling devices is shown in Fig. 6.

One of the main tasks of introducing electronic document management is the transition from paper documents to documents stored in a single database in electronic form $[15,16]$. For this, the procedure for entering data on devices is used.

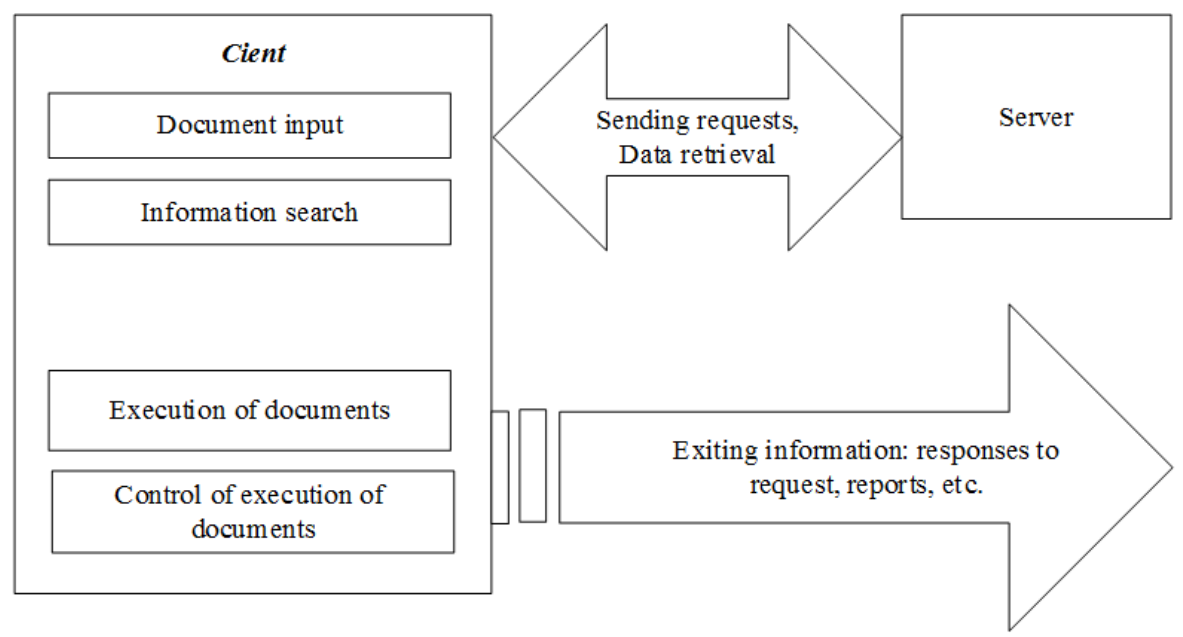

Fig.6. The scheme of functioning of the client of the automated system of accounting and control of signalling devices.

The required input fields when receiving data on devices include:

- brand (type) of the device;

- device serial number

- year of manufacture of the device (numerical value, without letters)

- verification period (in years)

- check period (in months)

- date of last check

- year of last inspection

- month of last check

- date of the upcoming (next) inspection

- year of the upcoming (next) inspection

- month of the upcoming (next) check

- installation date - date of installation of the device

- station/ferry — name of the station or ferry

- type of equipment — "cabinet", "cabinet", "relay cabinet"

- equipment designation - cabinet or relay cabinet designation 
- place in the equipment - shelf place (up to 4 digits) and sub place (letter and, if necessary, one number); the substitution can be omitted; spaces are not allowed;

- schematic designation name of the device on the diagram;

- device address - designation of equipment and shelf space, separated by a minus sign; spaces are not allowed.

\section{Conclusions}

After filling in the required fields, these data must be saved in the form of a database table, and the device must be assigned a serial number in the automated system. After that, further work with the system continues.

For quick access to information stored in a single database, a search procedure is required by various parameters. The main search parameters in the document management system include the brand and address of the device.

As a result, the functional features of the automated accounting and control system for signalling, centralization and blocking devices consist in the principle of building architecture, a scheme of functioning, and a procedure for changing data. Electronic document flow for control and accounting of railway automation and telemechanics devices in the form of ACA-SRAT significantly increases the efficiency of the automation and telemechanics economy and enterprises associated with this document flow.

The presented control and accounting system for automation and telemechanics devices using a QR-coding system is advisable to use for automatic identification of signalling devices to collect data on installed devices, check the correct replacement of devices, enter data on repair and acceptance, automated data input on new devices, received at the repair and technological areas.

\section{Reference}

1. Aripov N., Baratov D., Methods of constructing a mathematical model of electronic document management of technical documentation of railway automation, Automation in transport (3.) 1 pp.98-111, (2017)

2. Efanov D, Formation and development prospects of systems of functional control and monitoring of devices of railway automation and telemechanics, Automation in transport, (2), 1 pp.124-148, (2016)

3. Sedykh D., Sukhanov S.A., Application of the branch format of technical documentation for devices of railway automation and telemechanics for the integration of applications, Bulletin of the Petersburg University of Railways, 3 pp.6472, (2005).

4. Denisov B.P., Rubinstein N.I., Rastegaev S.N., Vorobey N.Yu., Automation of the design of railway automation and telemechanics systems based on AWP-PDD version 6 , Actual problems of the development of railway automation and telemechanics systems. 1 pp.33-38.

5. Aripov N Baratov D. Features of Construction of Systems of Railway Automatics and Telemechanics at the Organization of High-Speed, Traffic in the Republic of Uzbekistan Procedia Engineering, 134 pp. 175-180, (2016)

6. Baratov D. Aripov N Formalization of electronic technical document management of railway automatics and telemechanics Europaische Fachhochschule No.8 pp. 33-35, (2016) 
7. Vasilenko M., Denisov B., Bulavsky P., Sedykh D., Principles of organizing electronic document management of technical documentation, Transport of the Russian Federation Journal of Science Practice Economics, 7 (7) pp.61-66, (2006).

8. Shamanov V., The magnetic properties of rail lines and level of interferences for the apparatus of automatic control and telemechanics, Russian Electrical Engineering, 86, (9) pp.548-552, (2015)

9. Efanov D Plekhanov P, Ensuring traffic safety through technical diagnostics and monitoring of railway automation and telemechanics devices, Transport of the Urals.3 pp. 44-48, (2011).

10. Ibrahim S Ozgur T K Ilker U Galip C, Specication and formal verication of safety properties in a point automation system, Turkish Journal of Electrical Engineering \& AMP; Computer Sciences, 24 pp.1384-1396, (2016).

11. Baratov D Aripov N Muxiddinov O Jumanov X, Block diagram of the automatic model of technical documentation Journal of Physics: Conference Series, 1614, (1), p. 012032) IOP Publishing, (2020).

12. Yurkov N.K. Functional model of information technology for ensuring the reliability of complex electronic systems taking into account external influences Proceedings of the International Symposium, "Reliability and Quality" T. 1, (2014)

13. Baratov D. Astanaliev E., Using innovative technologies of electronic technical document management for railway automation and telemechanics, International Engineering Journal for Research and Development, 5 pp.5-9, (2020)

14. Dubranovsky I.V. Verification of C \#-programs: translation from C \#-light to C \# kernel //, Preprint of ISI SB RAS JV. p 120, (2004)

15. Vasilenko M. N. Electronic document management in railway signalling, Automation, communication, Informatics. 8. pp. 2-3, (2014)

16. Bulavsky P.E. Conceptual model of electronic document management of technical documentation, Transport of the Russian Federation, 1 (32). pp 60-63, (2011) 